\title{
Social Context of Child Survival Strategies among Mothers in Polygynous Marriages in Ibadan, Nigeria
}

\author{
Okechukwu S. Chukwudeh ${ }^{1}$ \\ Funmilola E. Ojo
}

Department of Sociology ${ }^{1}$

University of Ibadan, Ibadan, Nigeria

Department of Adult Education ${ }^{2}$

University of Ibadan, Ibadan, Nigeria

DOI:10.36108/NJSA/8102/61(0280)

\begin{abstract}
The study examined the social context of child survival strategies among mothers in polygynous marriages in Ibadan, Nigeria. The social exchange theory was employed as the theoretical framework. Thirty in-depth interviews were conducted with mothers in Polygynous marriages. Referral and snowball techniques were used to reach the target population. Mothers in polygynous marriages were purposively selected from three geographical locations in Ibadan, Nigeria. Manual content analysis was used to analyze the data for the study. The result showed that most mothers in polygynous marriages in Ibadan engaged in informal economic activities in order to raise finance needed for sustenance and child survival; use traditional herbs for child care, treatment and survival; live separately from other wives in order to prevent childhood sicknesses associated with congestion and overcrowding in the house. In addition, there is inconsistency in administering immunization to children due to poverty. The study concluded that mother's place of residence, health care practices, and engaging in informal economic activities positively influenced child survival among women in polygynous marriages in Ibadan. There is need for more awareness campaign to ensure that children in polygynous families are regularly administered with vaccines in order to ensure their survival and achievement of the Sustainable Development Goal 3.
\end{abstract}

Keywords: Child survival, economic activities, herbs, immunization, polygynous marriage

\section{Introduction}

Child survival strategies significantly determine the rate of mortality among under-five children. Due to high prevalence of childhood mortality in Africa, international organizations such as World Health Organisation (WHO), United Nation Children Education Fund (UNICEF), United Nation Organisation, World Bank, alongside various governments, and communities have designed some public health programmes aimed at improving child survival rate especially in sub-saharan Africa (Sobo, Oladoyinbo and Akintola, 2016; Akanbi and Anyarsor, 2014; Concern World, 2012; Habimana, Mwinga, Sagoe and Ketsele, 2010).

These programmes include those related to exclusive breastfeeding for the first 6 months, the use of insecticide treated nets (ITNs) for malaria prevention, 
anti-malaria drugs for treatment of malaria, micronutrient supplementation (vitamin A and zinc), immunization (especially hepatitis B, measles and tetanus), antenatal and postnatal care, sanitation (clean water and waste disposal), child growth monitoring, family planning, prevention of mother to child transmission of HIV through administration of an antiretroviral drug, oral rehydration solution (ORS) for diarrhoea, antibiotics for neonatal sepsis and pneumonia (UNICEF, 2014; Habimana, Mwinga, Sagoe and Ketsela, 2010). Yet, these child survival strategies designed by international organizations are not exhaustive.

In addition, communities make use of different strategies to ensure survival of children which aligns with the Sustainable Development Goal 3 is aimed at scaling up child survival among under-five children. Indeed, there have been global improvements as a result of socioeconomic development and implementation of child survival interventions (Sustainable Development Goal Report, 2016). However, millions of under-five children still die each year despite global decline estimated at more than half from 91 per 1000 live births to 43 per 1,000 live births between year 1990 to year 2015 (SDG Report, 2016).

In Nigeria, the number of under-five mortality is high despite socioeconomic development and efforts at reducing it by government and international agencies (Chukwudeh and Lawal, 2016). The country has adopted and implemented several major global initiatives affecting children such as the Safe Motherhood Initiatives and its follow-up Making Pregnancy Safer, Babyfriendly Hospital Initiatives (BFHI) among others (Chukwudeh and Lawal, 2016; Chukwudeh, 2015). In spite of these initiatives and programmes in Nigeria, the number of under-five mortality is still relatively high (Chukwudeh and Lawal, 2016; Chukwudeh, 2015).

In Nigeria, one in every eight children born between year 2008 and year 2013 died before their fifth birthday. Under-five mortality in Nigeria is estimated at 128 deaths per 1000 births and infant mortality is 69 deaths per 1000 live births (National Population Commission [Nigeria] and ICF International, 2014). The prevailing high mortality may be due to maternal social characteristics and practices which are predominant among mothers in polygynous marriages. Hence, it is against this back drop that this study shall examine the social context of child survival strategies among polygynous marriages in Ibadan, Nigeria.

\section{Brief Literature}

Polygynous family structure is a form of marriage that is common in Africa. This marriage pattern has implications for African demography (Cahu, Falilou and Pongou, 2011). Polygyny is a form of marriage or practice in which one man is simultaneously married to more than one woman at a given time. This form of marriage is widely practiced in Nigeria and in Africa. 
There is high under-five mortality in Africa and the death of a child most often results to conflict within the family as there are blames and counter blames after the death of a child which could lead to divorce in polygynous family setting (Kyei, 2011). Within polygynous families in Africa, when a child dies, the mother in most occasions blames other wives in the conjugal for her ordeal. This often leads to strife, conflict and at times divorce (Kyei, 2011).

In Nigeria, marriage is consummated for the purpose of procreation and is said to be fruitful when children are born and survive through time (Omage, 2013). Children are core element for marriage stability in Nigeria. A married woman who has not given birth after considerable time in the marriage is sometimes under pressure from the extended families. Also, Nigerian men consider themselves as accomplished only when their wives have children, which also serves as social security for the latter.

A woman who is barren is under constant threat of divorce from her husband. Many infecund women are sometimes maltreated by their husband and extended family members (Omage, 2013). In fact, within the social context of Nigeria, women are most likely to be blamed for a childless marriage. This situation is more evident in rural communities of Southwest Nigeria including Isiala-Mbano community of Imo state, where childless married couples are not regarded as a family (Nwazonobi, 2013).

The presence of children is very essential in any community and they are regarded as the future leaders of a community. Within the Nigerian communities, children are put into consideration during the formulation of social and economic plans because they constitute large proportion of the population in the country (Sule, Erigbali and Eruom, 2008). Marriage is not complete without children in the home. It is the presence of children that constitutes a family (Owoo and Bageant, 2017). In fact, children are the core of polygynous family as wives compete among themselves for more children. Polygynous marriage is a socially accepted form of marriage which is part of the traditional Nigeria society.

Studies have associated polygynous marriage with increased rate of child mortality in Africa (Gibson and Mace, 2007; Omariba and Boyle, 2007). Omariba and Boyle (2007) argue that there are many children in polygynous union, thus the father may not give adequate attention to the survival of a particular child. This implies that the father would not exert himself to ensure immunization, sound health care and survival of a particular child. The implication is that children in polygynous households would be less catered for and therefore exposed to a higher risk of death. In addition, the level of education of mothers in polygynous marriages has been implicated for the high prevalence of under-five mortality in polygynous households.

Similarly, Mulder (1992) stressed that insufficient wealth per capital may not be evenly distributed to all wives in a polygynous household. Thus, children would be vulnerable to under-nutrition and under-five mortality. On the other hand, Chisolm and Burbank (1991) emphasized that co-wives often co-operate in supporting each other in polygynous households and children 
may be catered for by other women in the conjugal even in the absence of their biological mother. In addition, Amankwa (1996) opined that Polygyny encourages prolonged breastfeeding and this itself ensures child survival.

Though, Strassmann (2000) observation of the Dogon people stressed that rivalry among co-wives could be harmful to child survival. However in Nigeria, it is possible that such rivalry among co-wives may serve as a motivation for each wife to strive to ensure optimum care and survival of her own children. This is because the survival of her children invariably determines the survival of her marriage, due to the importance of children in the family.

The child survival strategies which were developed by WHO, UNICEF and World Bank in year 2006, was aimed to scale up a defined set of effective child survival interventions, including antenatal care, immunization, new born care, use of insecticide treated net, and management of common childhood illnesses (Habimana, Mwinga, Sagoe and Ketsela., 2010). Irrespective of these strategies, Nigeria still experience relatively high prevalence of infant and child mortality. However, there has been considerable improvement in child survival rate in Nigeria as under-five mortality rate decreased from 201 deaths per 1,000 live births in year 2003 to 128 deaths per 1,000 live births in year 2013 (National Population Commission [Nigeria] and ICF International, 2014).

This improvement is more significant in South-west Nigeria despite the high rate $(16.3 \%)$ of polygynous marriage in the region (National Population Commission [Nigeria] and ICF International, 2014). Hence, this study will identify the child survival strategies adopted by polygynous families in Ibadan, the largest indigenous Yoruba community in southwestern Nigeria. Thus, there is need to understand the survival strategies adopted by polygynous families in southwest Nigeria and how it could be applied to other regions in Nigeria in order to reduce under-five mortality.

\section{Theoretical Framework}

This study is anchored on the social exchange theory. The theory is a social and psychological perspective that explains social change and stability as a process of negotiated exchanges between parties. Social exchange theory supposes that social relationships are result from some exchange processes. The tenet of the social exchange theory is that the relationships people choose to create and maintain are the ones that they will maximize rewards and minimize costs. According to this theory, people are more self-centered and not necessary concerned with equality. The basic idea is that, the relationships that give individuals the most benefits for the least amount of effort are the ones they value the most and are likely to keep long-term.

Marital relationships are determined and sustained by the benefit each partner derives from the conjugal (Gibson and Mace, 2007). On the one hand, males are more concerned about women that are physically beautiful, faithful, 
less expensive and give them children with both gender. Women on the other hand, are concerned about the financial freedom in their marital union (Baker, 2008; Whitty, 2008). Women thus would go into marital relationship simply for procreation (Omage, 2013) and other benefits such as protection, title such as "Mrs", and prestige associated with being married (Nwazonobi, 2013). It is these comparative advantages that women derived from marriage that motivates them to marry a man even if it requires them being second or third wives (Nwazonobi, 2013). In view of the above, it is not uncommon when married women perceived themselves to be superior over single ladies.

The social exchange theory stressed that people weigh the potential benefits and risks of social relationships. In like manner, people weigh the benefits they will derive from their conjugal. According to the theory, the benefits are things that the individual gets from the relationship such as fun, friendship, companionship, social support, sense of acceptance, procreation and survival of children (Aronson, 2003). The cost could be time (delay marriage), long time spent on acquiring higher education, unemployment and lack of money. This implies that due to delay in getting married which is the cost, female may accept to be second or third wife (which is the benefit) to curb the pressure associated with been single.

In addition, women often conduct a cost-benefit analysis to determine the initial value of each potential relationship by subtracting the perceived costs from the perceived benefits. People are attracted to each other for a variety of reasons that induce them to establish marital associations. Once initial ties are forged, the rewards they provide to each other serve to maintain and enhance the bonds. Although, a woman may dislike her husband's poor financial status and temperament but feels that the benefits (he is hardworking, handsome, caring, and fun to be around) outweigh the costs (Aronson, 2003; Zajonc, 2003).

According to social exchange theory, people use a cost benefit analysis at the beginning of the relationship to help them decide if they want to start it. They also continue to use cost benefit analysis as the relationship develops to decide if they want to continue it. Basically people compare the cost and benefit of their current relationship to the cost and benefit of their past relationship (Aronson, 2003; Zajonc, 2003). Male and female look at the costbenefit of their relationship or marriage, if there is no benefit (children) to their current marriage, they move ahead to marry someone else whether as second or third wives.

Male or female who are in their second marriage may also look at the costbenefit of their present marriage to determine it comparative advantage and disadvantage or go back to their previous marriage. Nigerians marry to have children and a couple without children often faces pressure from the extended family. Men marry women for procreation, and the society expects a married woman to give birth after a reasonable period of time (Nwazonobi, 2013).

In view of these, the presence of children serves as an exchange value between the couple in Nigeria or rather between the extended family members 
of the couple. This is because, in Nigeria, marriage is viewed as the union of two separate families coming together. In Nigeria, an infertile woman or wife is socially insecure as her husband may divorce her to marry another woman who can produce children for him. Thus, married women who had given birth to children always put effort to ensure sound health and survival of her children.

\section{Methods}

The study was conducted in Ibadan. Ibadan is the capital of Oyo state. The state is located in the Southwestern part of the country. The majority of the residents in Ibadan are Yoruba, but people from all ethnic groups in the country can be found in the city. The study adopted a cross sectional research design, and employed the qualitative technique. This is because of the sensitive nature of the subject under consideration. In-depth interviews were conducted among thirty mothers in polygynous marriage.

The mothers in polygynous families were identified by means of referral and snowballing technique. After each interview, the respondents were told to refer the researchers to other mothers in the community that were in polygynous marriage. Mothers who were interviewed are those who had given birth, indigenes of Ibadan, and had been in polygynous marriage for at least five years. The rational is because mothers who have given birth and their children are still alive would have some knowledge on the strategies they had used to ensure child survival.

Ibadan has eleven (11) local government areas and the residential structure of the city was divided into three homogenous groups: the core, the periphery, and the intermediate areas. The core areas are the traditional area of the city characterized by high level of poverty, high population density, lack of physical planning, dilapidated buildings, poor sanitation, and slum settlements.

The intermediate are areas of late development, mainly inhabited by migrants from other Yoruba towns and ethnic groups, or those who move out of family compound houses located in the traditional areas of the city. The density of the population here is lower than the traditional areas, and housing is also moderately scattered, although these are not well laid-out as those found in the peripheral areas.

The peripheral are well planned areas of the city that are inhabited by elites. These features well laid-out residential apartments, low density of population, and essential social services. A cluster of all the communities in the core, intermediate and peripheral were written in a sheet of paper. Then a community was selected from each of the location using simple random sampling. Using simple random sampling technique, Beree in Ibadan North east local government area (LGA) was selected from among the core areas, Orogun in Akinyele LGA was selected among the intermediate areas, and 
Bodija in Ibadan North LGA was selected among the peripheral areas. This makes up the three communities were the study was conducted.

Ten mothers were purposively selected from each of these areas (Bodija, Orogun and Beree) in order to include respondents from different categories of people based on their social status and housing structure. The researchers employed two female research assistants that are indigene of Ibadan for easy communication, accessibility and acceptability by the respondents. These female research assistants were needed since the topic was a sensitive one and their presence gave the respondents some level of confidence to express themselves.

The use of in-depth interview technique was relied upon to gather data for this study because it helps in the interpretative understanding of the subject under study. Comments from the respondents were recorded in a tape recorder. Themes were arranged based on the objectives of the study and manual content analysis was used for data analysis. This design also gives room for in-depth and intensive analysis of the phenomenon under study.

The in-depth interview guide was designed to examine the reproductive history and various child survival strategies employed by mothers in polygynous marriages amidst competition from other wives in the same conjugal. The qualitative instrument was used to collect data on the respondents' sources of income, place of residence, immunization and the means of health care system used by mothers in polygynous families in Ibadan, southwestern region of Nigeria.

\section{Limitation}

Despite the strength of the current study, which include it contribution to understanding the strategies of child survival among selected polygynous families in Ibadan, Nigeria. The use of In-depth interview in this qualitative study help us to gain interpretative understanding of the issues under discussion as it enables mothers who are in polygynous marriages to express themselves.

However, the study has some limitations. As a cross sectional study, the data were self-reported and the accuracy of the outcome of the study depends on the responds of the mothers in polygynous family interviewed at the study location. In addition, the study did not evaluate all the factors influencing child survival. The sampled size for the study is limited and probably the use of larger sample size may give different outcome to the study.

This is a qualitative study; the inclusion of quantitative aspect may add more details to the study. However, within the context of the study location and from the perspective of the women in polygynous marriage, the study was concerned with child survival strategies of mothers in polygynous marriage in Ibadan, Southwest Nigeria. 


\section{Results}

The findings of this study are presented along three objectives focusing on source of family income, the desired health care system employed by mothers in polygynous marriage, and the place of residence among mothers in polygynous marriage.

\section{Sources of Family Finance/Income}

Finance and income plays important role in child survival among polygynous families in Ibadan, Nigeria. This study showed that majority of the mothers in polygynous marriages in Ibadan engage in various informal commercial activities such as hawking, trading and street begging in order to raise money/income needed for optimal child care. This claim was substantiated by one of the participants in the In-depth interview, she noted:

Nowadays women have to learn a trade or/and engage in buying and selling in order to survive. For example, I have to hawk goods while still carrying my new born baby at my back. I do this every day in order to survive. My husband has five (5) wives and he does not have enough money to feed all of us adequately. So I have to help myself by selling goods in order to raise money to buy food to feed myself and my children. (IDI, 38years, Beree at Ibadan North East LGA, Polygyny family)

This shows that many mothers in polygynous marriage in Ibadan do not depend on their husband for household feeding. Mothers in polygynous marriages were not restricted to informal sectors but they also work in the formal sector in order to generate resources for home management. The view was advanced at Bodija by a participant who noted:

I teach in a secondary school. I am largely responsible for the provision of food in my family. My husband contributes little to the feeding and care of my children. This is because of the burden he has to shoulder in caring for all his wives and children at the same time. At the end of the day, he renders an insignificant financial assistance to me and my children. Thus, I have to help myself financially in order to properly provide the needs of my children and ensure they survive. (IDI, 28years, Bodija at Ibadan North LGA, Polygyny family)

Finance was essential for the survival of the under-five children in polygynous marriages. Thus, some mothers engaged in begging in order to raise fund for themselves. Another mother in a polygynous marriage stated:

Sometimes I tactically beg passerby on the street for money. It is shameful but I had to do it to help myself and my children. I am the only one caring for my children and it has not been easy for 
me. It is not my fault; I and my children must survive. (IDI, 40 years, Beree at Ibadan North East LGA, Polygyny family)

The presence of multiple wives in the family most likely increase the financial resources needed for optimal child care in polygynous marriages. And large family size may likely reduce the savings and economic growth of the household. Poor financial resources in polygynous households have negative implications for the health and wellbeing of under-five children in the family.

Since Nigeria is largely patriarchal, it is expected that the husbands provide for their households. However, many husbands are plague with unemployment and economic crisis in the country. Thus, many mothers in polygynous marriage in Ibadan engage in several economic activities in order to financially support themselves and their children.

In view of the above, many mothers in polygynous marriage in Ibadan assumed the responsibility of ensuring the survival of their children. A participant in the In-depth interview affirmed this when she said:

The numbers of wives my husband has do not affect the survival of my children. Every wife will face their own business by caring for their children. After all, how much property or income does my husband even have? It is the woman in the house that even ensures that her children eat everyday whether the husband brings money home or not. (IDI, 43years, Beree at Ibadan North East LGA, Polygyny family)

This shows that the quality of care given to children by their mother goes a long way to determine child survival. The engagement of mothers in informal economic activities increases the resources available at their disposal, which in turn influences the quality of care administered on children. The above comment was supported by an In-Depth Interview respondent:

Every woman has to struggle for herself and her children. These days most husbands with multiple wives do not care any longer about their children. If you disturb them, they will leave the home for you and go to live with another woman outside. That may lead to separation or divorce. And no woman can do anything about it. (IDI, 35years, Agbowo at Akinyele LGA, Polygyny family)

The significant economic role of mothers in polygynous marriages who live in Ibadan is that they engage in informal economic activities such as hawking, buying and selling, and street begging. This had assisted them to contribute to the upkeep of their children, thus ensuring their survival.

\section{Mode of Health Care System}

The methods of health care practices among mothers in polygynous marriages are essential to child survival. 


\section{Immunization}

Childhood immunization is essential for child survival in Nigeria. Adequate childhood immunization is a significant contributor to reduction in under-five mortality in Nigeria. Many mothers in polygynous marriages in Ibadan did not present their children for all the required vaccines due to paucity of fund. On vaccination of under-five children, a mother in an in-depth interview reported:

I did not give my daughter all the vaccines required for children except from the one given to her immediately after birth. I did not even attempt to immunize her because I do not have the money to pay for the vaccine. It is expensive. (IDI, 45years, Agbowo at Akinyele LGA, Polygynous family)

This view by the respondent above was reiterated by another respondent in the in-depth interview who noted:

I do not have money $(\# 6,000.00)$ for rotavirus vaccine. And you have to give your child twice (\#12,000.00). It is very expensive. The cost for immunization for children after 9 months is high. I cannot afford it. (IDI, 37 years, Bodija at Ibadan North LGA, Polygyny family)

The inconsistent administration of vaccines to under-five children in polygynous family was due to financial constraint. This in turn increases the risk of under-five mortality. Another respondent in the In-depth Interview stated:

Immunization is free for children between ages 0 to 9 months, but after then it involves money. Considering my current financial status, I cannot complete the vaccine or immunization for my son. (IDI, 57 years, Beree at Ibadan North East LGA, Polygyny family)

The finding above shows that children in polygynous marriages do not receive all the recommended vaccines for children because of the cost of administering the vaccines and this has serious health implications for child survival.

\section{Perception of Immunization}

The researcher further probed mothers' perception of childhood immunization. The study found that many mothers did not perceive that immunization was important to their children. A participant reported that:

Findings revealed that these investigations in most places lack scientific method. Responding to the manner of investigation, an adoption official submits: 
I do not think all these immunization is necessary. The important vaccine for children was given to them before they were discharged from the hospital, immediately after birth. All other vaccines are not necessary. (IDI, 49 years, Agbowo at Akinyele LGA, Polygynous family)

While some mothers perceived that the vaccine was not important to their children, other mothers had a contrary view. They believed that given children the necessary vaccine help prevent diseases. A respondent in the In-depth Interview said:

I know the vaccines are important for children. I endeavour to give my children the vaccines. The vaccine is good but it should be free because the cost of those vaccines scares parent away from administering it to their children. (IDI, 41 years, Bodija at Ibadan North LGA, Polygyny family)

The researchers' further probed mothers' willingness to administer vaccine to their children if vaccines were provided without financial cost. A respondent stated:

Yes I will give my child all the vaccine if it is free. Though, I have to consult my husband because I heard that those vaccines have negative consequences to children later in life. (IDI, 31years, Agbowo at Akinyele LGA, Polygyny family)

\section{Childhood Treatment Pattern}

The mothers in polygynous marriages reported that they preferred to use the traditional health care system for their children's' treatment and survival. According to them, the traditional herbal medications have been helpful in ensuring sound health for their new infant. A respondent in the In-depth interviews noted:

When I gave birth to my daughter in 1975, I gave birth at home with the assistance from a traditional birth attendant. This was because at that time my husband was financially handicap. And there was long distance between my place of residence/house and the modern health clinic. It was also difficult to get food supplements for children at that time. But at that time, I feed my daughter with a combination of yeast from fermentation gotten from cassava with breast milk for at least 3 months. And my daughter is healthy and alive till date. (IDI, 63years, Agbowo at Akinyele LGA, Polygyny family)

Traditional birth attendant and medication was used by mothers for safe delivery and care of their children. A participant in the In-depth Interview at Beree stated: 
I always make use of traditional herbs called "agbo" to take care of my infant health. Anytime I get pregnant, I often commence taking the traditional herb called "agbo" from when I become 5 months pregnant. I consume the traditional herb called "agbo" for easy labor and delivery. Even after given birth, I give my new infant the traditional herb called "agbo". The herbs have helped my little children to be healthy. It has been effective in managing the health of my children as all of them are healthy and alive. (IDI, 38years, Beree at Ibadan North East LGA, Polygyny family)

The traditional herbs were the major medication used by mothers in polygynous marriage to care for children. There are different types of herb that had been used by mothers in polygynous marriage to care for their children. Another respondent supported the above views of the use of traditional herbs to ensure infant and child survival. She said:

None of my children has died and none will die. Anytime my children fall ill, I will boil scent leaf ("Efinrin") and give them to drink. Even my little boy that cannot speak or say what is wrong with him; I give him scent leaf "efinrin" to clean his system or body from diseases that affect small children. (IDI, 31 years old, Bodija at Ibadan North LGA, Polygyny family)

Mothers in polygynous marriages in Ibadan, Nigeria make use of traditional herbs called "agbo" in Yoruba language for treatment of sick children and prevention of illness. The use of traditional herbs for health care is a common practice in Ibadan.

\section{Place of Residence among Polygynous Families in Ibadan}

The place of residence among mothers in polygynous marriage has implications for child survival in Ibadan, Nigeria. The result shows that most mothers in polygynous marriage do not live in the same house or compound with other wives in the same conjugal.

For example, if a mother is living in the family house with her husband, the other wives will prefer to live outside the family house or compound in order to avoid envy and hatred that often occurs when more than one wife live together in the same house or compound. One of the participants in the Indepth interview reported that:

I do not live in the same house with other wives of my husband. I do not want to die so early. I do not want them to use spirit medium (witch) to kill me and my children. That is why I left the family house and start living alone with my two children. (IDI, 38 years old, Agbowo at Akinyele LGA, Polygyny family) 
It was the belief of mothers that living together with other wives in the family will lead to conflict. This conflict was a risk to child survival because it often leads to spiritual attack which is dangerous to survival. This view was reiterated by another participant in the In-depth interview who stated that: You want them to kill my children? And without a child my husband will divorce me after some years. To protect my children and ensure their survival, I have to live separately from other wives. My brother I need to concentrate on my children well being that is why I stayed away from the family house. (IDI, 27 years old, Beree at Ibadan Northeast LGA, Polygyny family)

In addition, many mothers in polygynous marriage in Ibadan endeavoured to prevent their children from contacting diseases associated with crowded environment. This is because large family size leads to congestion which in turn affects the health of little children. A participant noted:

The family house is crowded and congested. We are about 20 people in 3 bedrooms flat. My children are still less than 5 years old. I do not want them to be exposed to infection in the family house. I need them alive to sustain my marriage. Hence, I live with my children alone, away from other extended family members. (IDI, 4lyears old, Bodija at Ibadan LGA, Polygyny family)

Most mothers in polygynous marriage in Ibadan do not stay in the same house with their fellow wives in the family in order to avoid congestion that may likely expose their children to infection, sickness and mortality.

Thus, the pattern of living separately from other women in the conjugal help mothers in polygynous marriages to cultivate strong emotional attachment to their children and ensured child survival.

\section{Discussion of Findings}

The study examined child survival strategies of mothers in polygynous marriage in Ibadan, Nigeria. The study found that most mothers in polygynous marriage were largely responsible for their children feeding, healthcare and survival. This is in agreement with Nwazonobi (2013) who argued in her work on polygamy in Isiala-Mbano that polygynous marriages persist because women strive to avoid the challenges associated with being single. The social exchange theory explains this kind of relationship in the Nigeria environment. In view of the above, the study concludes that child bearing and rearing are significant determinant to marriage stability in the study locations. Thus, mothers in polygynous marriages sustained their marriages by hawking goods or trading, and at times begging on the street in order to raise finance to feed and care for their children.

In a study conducted in Nigeria, Onyejekwe (2001) opined that about half of Nigeria populations are women who have always played significant 
economic roles. Similarly, World Bank (2011) reported that women constitute $40 \%$ of the global workforce and they contribute to the enormous work in the households which include child care. In addition, Fapohunda (2012) opined that women dominate the informal economic sectors in Nigeria. These findings are in harmony with the social exchange theory which explains that the engagement of women in several economic activities was as a result of the inherent benefit accrued to them. This study, using qualitative method discovered that mothers in polygynous marriages in Ibadan engage in several informal economic activities to enable them support their family financially and care for the needs of their children in order to ensure child survival.

The importance of immunization for reduction of under-five mortality cannot be over emphasized. In the study location, while some mothers agreed that disease preventable vaccines are necessary for children survival, others had a contrary perception. The cost of the vaccines was a barrier for consistent immunization of under-five children. Studies had earlier reported that children is polygynous marriages do not regularly receive immunization (Gyimah, 2002). This study has established that mothers in polygynous marriages are constraints to give their children immunization due to poverty.

With regard to the mode of healthcare system used by mothers in polygynous marriages in Ibadan Nigeria, the In-depth Interview indicated that most mothers in polygynous families make use of the traditional health care system. Despite improvement in the modern health care industry, most mothers in polygynous marriages still prefer the traditional health care system for the treatment and care of their children. They have high trust and confidence for the traditional herbal medicine as this was often used during pregnancy for easy delivery and after child birth for cleansing of the women internal system. In the context of the social exchange theory, the patronage of traditional health care was due to the benefits mothers derived from it. This finding is similar to a study in Nigeria by Nwokocha (2008) that reported that many Nigerians perceived unorthodox treatment provided by traditional health practitioners and faith based healers as effective.

Also mothers in polygynous marriages administer traditional herbs (agbo) to new infant. There is strong affiliation for traditional herbal medicine and this is due to the tradition, culture and belief system of the people. Using the exchange theory to explain this finding, the theory explained how the presence of children (benefit) helps sustain marital relationship in Ibadan, Nigeria. The inability of a woman to procreate may lead to termination of the marriage, divorce or the husband getting married to more wives (Polygyny). In line with this, Nwazonobi (2013), opined that it is the benefit women attach to marriage that makes them to accept to be in polygynous marriage and they endeavour to sustain such marriage at minimal cost such as the use of non-expensive traditional herbs. 
Place of residence of the mothers in polygynous marriages plays a significant role to the survival of children. Owo (2018) posits that the average household size of polygynous household is 9.43 members. This has negative health implications for under-five children who could easily contact infectious diseases due to overcrowded households. However, this study reveals that most mothers in polygynous marriages in Ibadan Nigeria do not reside in the same house with other wives in the conjugal. This is due to fear, jealousy or hatred that is often associated with women in polygynous marriage.

And in order to avoid conflict with other wives and prevent any harm to their children, they often live in a different house away from other wives in the conjugal. This also helps prevent overcrowding in the house which could have led to diseases that affect little children in the house. This finding is consistent with Wadha and Dudley (2015) who reported that $60 \%$ of women in polygynous marriages do not live in the same house with co-wives in the conjugal.

In line with the social exchange theory, most women in polygynous marriages in Ibadan Nigeria perceive the benefit of being married to their husband as highly beneficial. Living apart or away from their husband and most times being responsible for household expenses are the challenges or cost of polygynous marriages. However, the marriage has been sustained by the perceived benefits which include among others the birth and survival of children in the family.

\section{Summary and Conclusion}

There is an improved level of child survival among polygynous families in Ibadan, Nigeria. Using the Social exchange theory, this study revealed that sources of income, mode of child health care and mother's place of residence influenced child survival among polygynous families in Ibadan, Nigeria. Results also indicated that mothers in polygynous families are largely responsible for the feeding and care of their children. They had to engage in trading and hawking of goods to financially support themselves.

In addition, that mothers in polygynous families make use of traditional herbs, which are relatively less expensive for treatment of their children. Most children in polygynous families were not vaccinated due to poverty. Mothers in polygynous marriages live in separate houses away from other wives to avoid overcrowding, congestion and dispute associated with living with other wives. Insights from this study will be useful for interventions that target attainment of Sustainable Development Goal-3 in Nigeria. Given that there is inconsistency in administering vaccination to under-five children, more awareness campaigns are needed to ensure that under-five children in polygynous households are vaccinated as and when necessary.

\section{References}

Akanbi, F.O.M. and Anyarsor, C. (2014) Growth monitoring: the key to child survival strategy in Nigeria. J. Res. Nurs. Midwifery, 3(2): 31-38. 
Alnuaimi, W.S and Dudley, L.P. (2015) Polygyny and fertility in the United Arab Emirates at the end of the 20th century.

Amankwa, A.A. (1996) Prior and proximate causes of infant survival in Ghana with special attention to polygyny. Journal of Biosocial Science, 28: 281295.

Aronson, E. (2003) The social animal. New York: Freeman.

Baker, A. (2008) Down the rabbit hole: The role of place in the initiation and development of online relationships. In A. Barak (Ed.). Psychological aspects of cyberspace: Theory, research, applications, pp. 163-184, Cambridge, UK: Cambridge University Press.

Cahu, P., Falilou, F., Pongou, R. (2011) Demographic Transition in Africa: The Polygamy and Fertility Nexus. Centre D'Economiedela Sorbonne, Universite Pantheon-Sorbonne, MSE 106-112.

Chisolm, J.S. and Burbank, V.K. (1991) Monogamy and polygyny in southeast Arnhem Land: Male coercion and female choice. Ethology and Sociobiology, 12: 291-313.

Concern World (2012) Focus on Rwanda-CHILD SURVIVAL; How can we ensure that all children survive the first five years of life? Retrieved from http//www.who.int/countries/rwa/rwa/en.

Chukwudeh, S.O. (2015) The influence of household income on under-five mortality in Ibadan, southwest Nigeria. The American journal of innovative research and applied sciences, 1(10): 389-396.

Chukwudeh, S.O. and Lawal, A. (2016) Mothers economic resources and under-five mortality in Ibadan, Southwest Nigeria. International Journal of Research, Vol. 3, Issue 1.

Fapounda, T.M. (2012) Women and the informal Sector in Nigeria: Implications for Development. British Journal of Arts and Social Sciences, $4(1)$.

Gibson, M.A. and Mace, R. (2007) Polygyny, reproductive success and child health in rural Ethiopia: why marry a married man? Journal of Biosocial Science, 39(02): 287-300. DOI.

Gyimah, S.O. (2002) Ethnicity and Infant Mortality in sub-Saharan Africa: The case of Ghana. Population Studies Centre Discussion Paper, No. 02-10. The University of Western Ontario, London, Ontario, Canada.

Habimana, P., Mwinga, K., Sagoe, M.C., Ketsela, T. (2010) Progress in implementing the child survival strategies in the Africa region. The Afr. Health monitor issue, 11: 18-23.

Kyei. K.A. (2011) Socio-economic factors affecting under-five mortality in South Africa- An investigative study. Journal of emerging trends in economic and management sciences, 2(2): 104-110.

Mulder, M.B. (1992) Women's strategies in polygynous marriage: Kipsigis, Datoga and other East African cases. Human Nature, 31: 45-70. 
National Population Commission (NPC) [Nigeria] and ICF International (2014) Nigeria Demographic and Health Survey. Abuja, Nigeria, and Rockville, Maryland, USA, pp. 32-256.

Nwazonobi, P.E. (2013) Polygamy in Dialogue with ethics: A case study of Isiala-Mbano Local Government Area of Imo State, Nigeria. Ilorin Journal of Religious Studies (IJOURELS), 3(2): 117-132.

Nwokocha, E.E. (2008) Traditional Healthcare Delivery Systems in the 21st Century Nigeria: Moving beyond Misconceptions. World Health and Population, 10(1): 23-32.

Omage, M.I. (2013) Critical issues in marriage failure in Benin city, Nigeria: Signaling the way forward. European Scientific Journal, 9(5).

Omaribo, S.W.R. and Boyle, M.H. (2007) Familial structure and child mortality in sub-saharan Africa: Cross national effect in Polygyny. Journal of Marriage and Family, 69(2): 528-543.

Owo, N.S. (2018) Food insecurity and family structure in Nigeria. Population Health, 4: 117-125.

Owoo, N.S. and Bageant, E. (2017) Food insecurity and family structure in Nigeria. A paper presented at the 2017 Agricultural and Applied Economic Association Annual Meeting, Chicago, Illunois. July 30-August, 2017.

Onyejekwe, C. (2001) Micro Finance and Economic Empowerment: Women`s Co-operatives in Nigeria. Asian Journal of Women 's Studies, 7(4): 70-89.

Sobo, A.A., Oladoyinbo, C.A. and Akintola, O.S. (2016) Knowledge and practice of mothers on child survival strategies in Odeda local government area, Ogun state, Nigeria. Journal of Research in Nursing and Midwifery, 5(3): 055-062.

Strassmann, B.I. (2000) Polygyny, family structure, and child mortality: A progressive study among the Dogon of Mali. In Lee cronk, Napoleon chignon and Williams iron (Eds.). Adaptation of human behavior; An Anthropological perspective, pp. 49-67. New-York: Aldinede Greyter.

Sule, J.O., P. Erigbali, L. Eruom (2008) Prevalence of infertility in women in a southwestern Nigerian community. African Journal of Biomedical Research, 11: 225-227.

Sustainable Development Goal (2016) Monitoring water and sanitation in the 2030 agenda for sustainable development. An introductory guide. Retrieved from $t t t p: / / w w w . u n w a t e r . o r g / s d g s / e n$.

UNICEF (2014) Committing to Child Survival: A Promise Renewed; Progress Report 2014 retrieved from http//www.unicef.org/Committing to Child Survival: A Promise Renewed; Progress Report.

Whitty, M.T. (2008) Revealing the real 'me', searching for the actual 'you': Presentations of self on an internet dating site. Computers in Human Behavior, 24(4): 1707-1723.

World Bank (2011) World Development Report 2012. Gender Equality and Development, Washington.

Zajonc, R.B. (2003) The Selected Works of R.B. Zajonc. New York: Wiley. 